\title{
Universal reaction norms for the sustainable cultivation of hybrid poplar clones under climate change in Italy
}

\author{
Maurizio Marchi ${ }^{(1)}$, \\ Sara Bergante ${ }^{(2)}$, \\ Duncan Ray ${ }^{(3)}$, \\ Roberto Barbetti ${ }^{(2)}$, \\ Gianni Facciotto ${ }^{(2)}$, \\ Pier Mario Chiarabaglio ${ }^{(2)}$, \\ Jari Hynynen ${ }^{(4)}$, \\ Giuseppe Nervo ${ }^{(2)}$
}

(1) CNR, Institute of Biosciences and BioResources - IBBR, Division of Florence, v. Madonna del Piano 10, I-50019 Sesto Fiorentino, FI (Italy); (2) CREA - Research Centre for Forestry and Wood, s.da Frassineto 35, I-15033 Casale Monferrato, AL (Italy); (3) Centre for Ecosystems Society and Biosecurity, Forest Research, Roslin, EH25 9SY Scotland (UK); (4) Natural Resources Institute Finland - LUKE, Latokartanonkaari 9 , FI-00790 Helsinki (Finland)

@ Sara Bergante (sara.bergante@crea.gov.it)

Received: Oct 04, 2021 - Accepted: Jan 12 , 2022

Citation: Marchi M, Bergante S, Ray D, Barbetti R, Facciotto G, Chiarabaglio PM, Hynynen J, Nervo G (2022). Universal reaction norms for the sustainable cultivation of hybrid poplar clones under climate change in Italy. iForest 15: 47-55. - doi: 10.3832/ifor3989-015 [online 2022-02-08]

Communicated by: Gianfranco Minotta

The cultivation of hybrid poplar clones is increasing worldwide. Hundreds of hectares of plantations now occur across Europe and other continents such as North America, using tested clones and novel genotypes. Research effort aims are to develop fast growing disease- and pest-resistant clones to improve production quality and quantity. In this study the phenotypic plasticity of poplar clones was tested across environmental and temporal gradients. The growth performance of 49 hybrid poplar clones recorded between 1980 and 2021 was analysed using a mixed-effects model with climatic data as a predictor variable. Clones were aggregated into two groups according to their breeding protocol (i.e., standard clone, and improved material) and their growth modelled for future climate scenarios of RCPs 2.6 and 8.5 using a downscaled version of the variants 01 and 21 of UKCP18 climate projections dataset for three 30year normal period time-slices: 2030s, 2040s, 2050s. The fitted growth models showed highly significant results, explaining more than $85 \%$ of the variance, with a mean relative absolute error of approximately $2 \%$. Improved material showed more resistance to warmer and drier climates and less sensitivity to the changing climate. While no unique pattern was found when comparing growth performances, new improved clones were more productive than older clones (e.g., ' I-214') with an additional benefit of resistance to rust and pests. Spatial predictions confirmed the Po valley as the most important geographic area for poplar cultivation in Italy, but zones in Central and Southern Italy show potential. However, the Po Valley is also where poplars are predicted to be suitable in the next decades with large uncertainties. The analysis identified the need for more research on the topic of poplar breeding. For example, models using the most extreme (warm and dry) climate projection, variant 01 of RCP8.5 of the UKCP18, exceeded the historic climate threshold, and predictions used model extrapolation, with associated statistical uncertainty. Therefore, predictions should be considered with care and more research effort is required to test clones over wider environmental conditions.

Keywords: Forest Tree Breeding, ClimateDT, Universal Response Function, B4EST

\section{Introduction}

Poplar (Populus spp.) clones form one of the main resources for productive plantation forestry worldwide, with thousands of hectares planted for plywood, roundwood or biomass (Schreiber et al. 2013, Bergante et al. 2020). Specialized poplar cultivation has for decades contributed to the development of important economic and productive sectors such as paper, wood-based plywood and furniture, by providing highquality raw materials. This production has been supported by the identification and deployment of new genotype clonal selection (Lefèvre et al. 2001). Besides the ability to remove $\mathrm{CO}_{2}$ from the atmosphere the use of poplar timber for long-lasting woodbased products is an important carbon store. Long-lived products for furnishing and construction are obtained from specialized poplar plantations grown at a spacing layout of $6 \times 6$ meters and with a rotation period of 10-12 years (Winans et al. 2015). This planting arrangement additionally contributes ecosystem services bene- fits to society, such as climate change mitigation and environmental and landscape improvement in rural areas. Poplar trees are cultivated globally with approximately 31.4 million hectares. The largest plantations occur in Canada and China, followed by Europe with France and Italy providing the main areas of plantation. In Italy, about 43,400 hectares are located in Northern Italy in the Po valley (Corona et al. 2020). Historically, specialized poplar plantations in Northern Italy have continued to be grown due to the cultural dependence of expert knowledge and tradition. The production of poplar wood has a particular importance in the internal wood-furniture and paper sector. However, it does not cover the demand from industry, which is increasingly interested in optimizing supplies through an in-depth knowledge of the areas of growth and regional cultivation. In Italy an inventory of poplar crops has now been completed (Corona et al. 2020) but the likely future impact of climate change on cultivation and production is unknown. 
To date there are no results from ecological studies to evaluate the influence of environmental drivers on poplar clones in Italy.

Spatial modelling of forest tree species niche suitability provides a useful technique to support forest management strategies and conservation planning (Schueler et al. 2014, Booth 2018). Among the range of tools and algorithms currently available, several conceptual approaches have been developed. The first and oldest group is represented by Species Distribution Modelling techniques (SDM), where the spatial distribution of a target species is considered as a proxy of its realised niche (Elith et al. 2006, Pecchi et al. 2019). While SDM techniques have been used widely across time and space (Isaac-Renton et al. 2014, Tang et al. 2020), their shortcomings have been recognised, such as the need to ac-

Tab. 1 - List of trials included in this study and main average climatic parameters occurred over the growing period of clones (10 years). The variables bio1 and bio12 represent the mean annual temperature $\left({ }^{\circ} \mathrm{C}\right)$ and the mean total annual precipitation $(\mathrm{mm})$, respectively, while AHM (annual heat moisture index, ${ }^{\circ} \mathrm{C} \mathrm{m}^{-1}$ ), bio4 (temperature seasonality, $\mathrm{sd}^{\circ} \mathrm{C} \cdot 100$ ) and MSP (mean summer precipitation, $\mathrm{mm}$ ) are the variables we used for modelling.

\begin{tabular}{|c|c|c|c|c|c|c|c|c|c|}
\hline Site name & $\begin{array}{r}\text { Establ. } \\
\text { (year) }\end{array}$ & $\begin{array}{c}\text { Long } \\
\text { E }\end{array}$ & $\begin{array}{c}\text { Lat } \\
\mathrm{N}\end{array}$ & $\begin{array}{c}\text { Elev } \\
(\mathrm{m}) \\
\end{array}$ & bio1 & bio12 & $\mathrm{AHM}$ & bio4 & MSP \\
\hline Azienda Cesurni & 1990 & 12.72377 & 41.94512 & 53 & 16.4 & 681.8 & 38.8 & 649.7 & 207.6 \\
\hline Azienda Ovile & 1990 & 12.3556 & 41.90792 & 43 & 16.5 & 708.8 & 37.4 & 635.7 & 188.7 \\
\hline Azienda Scottine & 1990 & 9.48700 & 45.06267 & 55 & 14.3 & 814.0 & 29.8 & 752.8 & 326.0 \\
\hline Azienda Volpares & 1985 & 13.09427 & 45.79843 & 7 & 13.9 & 1176.2 & 20.3 & 737.6 & 511.7 \\
\hline Brisighella & 1982 & 11.76317 & 44.21714 & 106 & 14.1 & 730.1 & 33.0 & 745.5 & 280.8 \\
\hline Carpaneta & 2007 & 10.88056 & 45.17917 & 24 & 14.9 & 732.8 & 34.0 & 761.9 & 317.9 \\
\hline Castiglion d & 1986 & 10.94816 & 42.82812 & 52 & 15.9 & 574.3 & 45.1 & 622.5 & 177.5 \\
\hline Cavagnolo & 2012 & 8.08833 & 45.16861 & 153 & 14.7 & 730.7 & 33.8 & 757.5 & 298.9 \\
\hline Cavarzere & 2007 & 11.97333 & 45.14 & 4 & 15.2 & 688.8 & 36.6 & 753.8 & 298.5 \\
\hline Ceva & 2000 & 8.0002 & 44.38667 & 445 & 13.0 & 602.3 & 38.2 & 691.2 & 229.6 \\
\hline Dronero & 2000 & 7.38583 & 44.45472 & 605 & 11.9 & 645.0 & 33.9 & 708.2 & 289.0 \\
\hline Feltre & 1982 & 11.93074 & 46.03544 & 338 & 11.5 & 930.5 & 23.1 & 742.3 & 464.4 \\
\hline Frassinello & 2004 & 8.40611 & 45.04611 & 142 & 14.3 & 634.8 & 38.2 & 758.3 & 264.0 \\
\hline Gabiano & 2003 & 8.20361 & 45.17389 & 143 & 14.2 & 661.6 & 36.5 & 779.0 & 284.9 \\
\hline Grassaga & 1987 & 12.59043 & 45.67981 & 1 & 14.1 & 1059.0 & 22.8 & 719.4 & 471.7 \\
\hline Istrana & 1984 & 12.08753 & 45.68105 & 37 & 13.8 & 935.6 & 25.4 & 744.5 & 430.9 \\
\hline Lorenzana & 1991 & 10.52623 & 43.53259 & 41 & 15.6 & 722.7 & 35.4 & 648.8 & 235.5 \\
\hline Marsicovetere & 1983 & 15.84118 & 40.34179 & 612 & 13.0 & 536.4 & 43.0 & 635.7 & 143.7 \\
\hline Mezzi & 1997 & 8.5125 & 45.13722 & 105 & 14.4 & 700.4 & 34.8 & 756.8 & 302.9 \\
\hline Mezzi-Baldo & 2013 & 8.50639 & 45.14056 & 106 & 15.1 & 701.3 & 35.8 & 761.1 & 261.4 \\
\hline Migliarino & 1991 & 10.30831 & 43.75409 & 1 & 15.8 & 778.1 & 33.1 & 660.6 & 241.1 \\
\hline MolinellaMarmorta & 1993 & 11.72237 & 44.61177 & 4 & 15.1 & 639.9 & 39.2 & 744.1 & 267.8 \\
\hline Mombello & 2006 & 8.28972 & 45.115 & 146 & 14.3 & 643.6 & 37.8 & 752.9 & 274.3 \\
\hline Monticello d'Alba & 1992 & 7.93583 & 44.71778 & 267 & 13.6 & 693.1 & 34.1 & 700.3 & 343.9 \\
\hline Piopp.Pisano & 2004 & 8.49944 & 45.09167 & 121 & 14.4 & 697.1 & 35.0 & 760.1 & 279.1 \\
\hline PoggioUgolino & 1993 & 11.29399 & 43.69585 & 205 & 14.5 & 746.4 & 32.8 & 701.5 & 254.1 \\
\hline Rosignano M.mo & 2000 & 8.42111 & 45.06694 & 151 & 14.0 & 692.9 & 34.6 & 760.5 & 295.1 \\
\hline San Basilio A.P. & 1979 & 12.18473 & 44.95184 & 1 & 14.2 & 619.0 & 39.1 & 750.8 & 280.4 \\
\hline Sant'Agata & 2004 & 11.20417 & 44.64694 & 17 & 15.1 & 669.4 & 37.5 & 766.5 & 249.3 \\
\hline Trino & 2003 & 8.30833 & 45.185 & 131 & 14.2 & 637.4 & 38.0 & 781.4 & 275.6 \\
\hline
\end{tabular}

common garden genetic trials and is able to evaluate the genetic adaptation (or variation) and the phenotypic plasticity of a phenotype in a single model.

The modelling framework for a sustainable and cost-efficient cultivation of polar clones in this study is inspired by the approach forest geneticists now adopt to analyse and summarize the performance of different provenances across ecological gradients (Hemery et al. 2005, Pukkala 2017). In this paper we propose such a modelling framework for hybrid poplar clones in Italy. Data between 1980 and 2021 for 49 poplar clones widely tested in Italy were here clustered in two groups and single-group reaction norms were calculated to predict the potential productivity across time and space.

\section{Materials and methods}

Species Distribution Model (SDM) terminology and techniques have a clear conceptual scheme and usage. However, there is no clear boundary between Response Functions (RF), Transfer Functions (TF) and Reaction Norms (RN) since all of them deal with the variability of a measured trait across an ecological gradient. In addition, RF and TF have been often pooled across planting sites using more sophisticated techniques (e.g., mixed-effects models), and the term "Universal" added to the name of the approach. To be clear, in this study, we use the following semantic structure:

- Response Function (RF): the genetic expression of a single genotype across the range of ecological distance from the climate of origin;

- Transfer Function (TF): the genetic expression of a single genotype across the range of ecological distance from the climate of origin using a spatial coordinate system predictor;

- Reaction Norm (RN): the pattern of phenotypic plasticity of a single genotype across a range of environments;

- Universal Response Function (URF), Universal Transfer Function (UTF) and Universal Reaction Norm (URN): models where the response/reaction of different genotypes or provenances is pooled in a unique model using various mathematical techniques.

According to this hierarchical structure, the URN concept will be used for the models developed in this study, since no climate of origin can be derived for clones, no spatial predictors were used, and genotypes (i.e., poplar clones) were pooled into groups.

\section{Clonal materials and experimental network}

The dataset used consists of 49 poplar clones from various poplar species tested across Italy, though cultivation and production is more abundant in Northern Italy. Clones in our study cover almost all the historical breeding effort including old and ex- 
Fig. 1 - Ecological distribution of the 30 trials considering the two main climatic parameters (AHM for aridity and bio4 for continentality) and abundance of tested clones across considered sites.

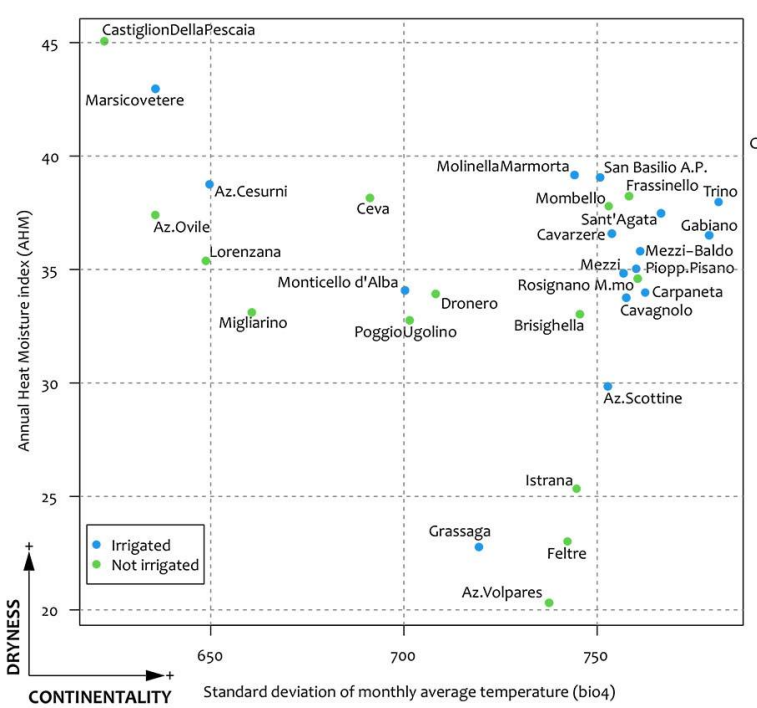

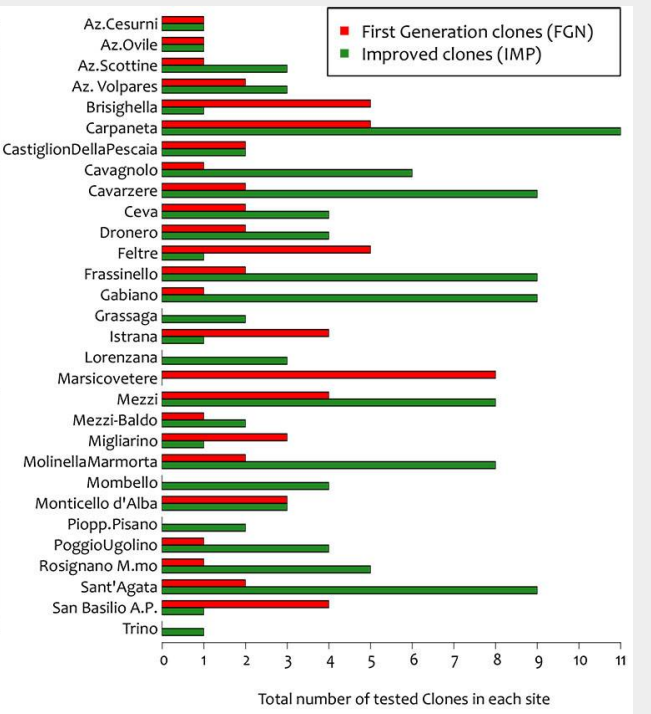

perimental clones, and we grouped these into two main clusters based on characteristics that include: years of selection (starting from 1929 to present), expected production ability, pest and disease resistance. The names of these two groups were First GeNeration clones (FGN) and IMProved clones (IMP), the latter include the newest Italian MSA (Maggiore Sostenibilità Ambientale or Higher Environmental Sustainability) clones. All the tested clones and their groups are reported in the online supplementary material (Tab. S1).
The experimental network is geographically focused on Northern Italy, mainly across the Piedmont, Lombardy, Veneto and Emilia-Romagna regions, but also including some trials in Central Italy and the Mediterranean region (Tab. 1).

A total of 30 trials with different planting years (between 1980 and 2013) were analysed and clones were irregularly distributed across a wide range of climate (Fig. 1). All the trials and data were characterised by a standardised cultivation scheme maintained across time and space.
Two-year-old cuttings were always used as starting material and established with 36 $\mathrm{m}^{2}$ of space available for each tree (spacing of $6 \times 6$ meters) with a final harvest at the age of 10 or sometimes 12 . The cultivation trials followed the standard model for poplar growth with small differences due to the layout of each farm, and irrigation. Irrigation is a common practice in poplar cultivation but not all the trials were irrigated due to pedo-climatic conditions, or the lack of irrigation infrastructure. For this reason, irrigation was added into the

Fig. 2 - Temporal sampling across sites between 1980 and 2012.

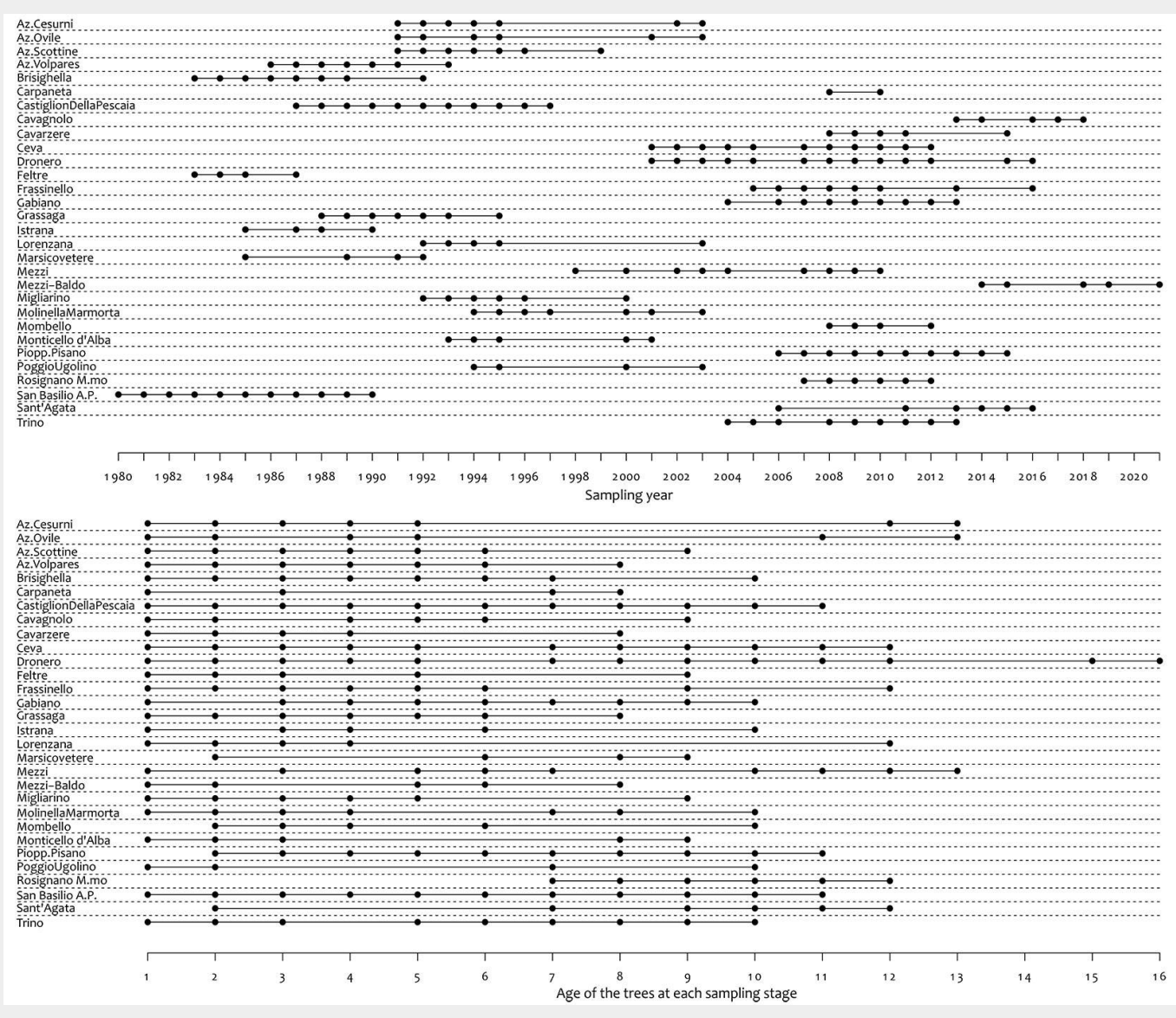


model as a dummy variable.

According to the wide range of measurements and ages across the dataset (Fig. 2) a large degree of variability between trials was observed. Given that the main product from poplar cultivation is harvested at age 10 and considering that most of the plots were presenting data for this age, a common age of 10 years after planting was used as the standard measurement for growth of poplar clones, avoiding extensive extrapolation across the dataset.

In this work a sigmoid function was used to interpolate the single-clone average diameter at breast height (DBH) at age 10 for trials where this record was missing. Single-clone average DBH was the simple arithmetic mean of the measured trees and among all the possible sigmoid functions available in literature we selected the Gompertz function (Pretzsch 2009) whose equation was as follows (eqn. 1):

$$
D B H=k \cdot e^{-a e^{-b x}}
$$

where $k, a$ and $b$ are the parameters to be estimated and $x$ is the age of the tree. Among the large family of sigmoid functions this model was selected given its ability to be asymmetric on the cartesian axes (i.e., the inflection point is not forced to centre of the range of $y$ values).

\section{Modelling framework: climatic}

characterizations and predictors

A reaction norm captures the phenotypic expression of a trait for a single genotype across a range of environments. For every genotype, phenotypic trait, and environmental variable, a different reaction norm can be calculated. In forest science this kind of information is generally handled by means of a mixed modelling approach where fixed effects are selected climatic variables and the site variation is a random effect. However, the use of clones did not allow us to calculate an ecological distance (i.e., climate of the origin vs. climate of the trial), thus the two clonal groups were modelled separately using the clone as a random effect. Therefore, the growth of poplar clones belonging to the same group was modelled across sites and then merged statistically in the mixed-effects model using DBH at age 10 as the target trait.

Tailored climatic data for all the trials in Italy were derived from ClimateDT (https:// ibbr.cnr.it//climate-dt/), a web portal where scale-free climatic data are provided freely at global level using CRU-TS data (Harris et al. 2020) for the historical period (1901-current year) and UKCP18 for the future period until 2098 (Lowe et al. 2019). This system is an online version of the ClimateEU (Marchi et al. 2020) and Climate NA (Wang et al. 2016) software and implements a scale-free dynamic downscaling, providing more than 100 climatic variables and indices for ecological analysis, spatial prediction and research purposes in general. ClimateDT was used twice in the study: firstly the historical climate for all the 30 trials was requested and 10-year averages were calculated to describe the climate of each trial between establishment and harvesting (i.e., when the diameter at age 10 was measured). Secondly, spatial layers for $30-$ year climate normal periods for the current climate (average 1991-2020) and three future scenarios (2030s: 2016-2045; 2040s: 2026-2055; and 2050s: 2036-2065) were calculated using two variants (numbers 01 and 21) from the perturbed physics ensemble (PPE - Lowe et al. 2019) of UKCP18 scenarios RCP2.6 and RCP8.5. These scenarios represent the range of representative concentration pathway (RCPs) scenarios available from the Fifth Assessment Report (AR5). We used ClimateDT to generate climate data rasters with a spatial resolution of $250 \mathrm{~m}$ for spatial prediction across time and space.

In this work, we followed the model format used by several previous studies (Berlin et al. 2016, Benito Garzón et al. 2019,

Tab. 2 - Results of the model fitting. FGN model: $R^{2}=0.858, F x=0.823, R n=0.034$; IMP model: $\mathrm{R}^{2}=0.843, \mathrm{FX}=0.815, \mathrm{Rn}=0.029$.

\begin{tabular}{|c|c|c|c|c|c|c|c|c|}
\hline \multirow[b]{2}{*}{ Predictor } & \multirow{2}{*}{$\begin{array}{c}\text { FGN model } \\
\text { Estimate }\end{array}$} & \multicolumn{7}{|c|}{ IMP model } \\
\hline & & $\begin{array}{l}\text { Std. } \\
\text { Error }\end{array}$ & $\operatorname{Pr}(>|t|)$ & Sig & Estimate & $\begin{array}{l}\text { Std. } \\
\text { Error }\end{array}$ & $\operatorname{Pr}(>|t|)$ & Sig \\
\hline Intercept & 1778 & 301.4 & $6.81 \mathrm{E}-07$ & $* * *$ & 1859 & 320.9 & $1.33 \mathrm{E}-07$ & $* * *$ \\
\hline $\mathrm{AHM}$ & -11.170 & 7.655 & 0.152876 & - & -8.061 & 8.299 & 0.334252 & - \\
\hline $\mathrm{I}\left(\mathrm{AHM} \mathrm{M}^{2}\right)$ & -0.162 & 0.042 & 0.000463 & $* * *$ & -0.147 & 0.048 & 0.00318 & $* *$ \\
\hline bio4 & -4.451 & 0.572 & $1.71 \mathrm{E}-09$ & $* * *$ & -4.996 & 0.549 & $5.39 \mathrm{E}-14$ & $* * *$ \\
\hline I(bio4 $\left.{ }^{2}\right)$ & 0.002 & 0.000 & $<0.000001$ & $* * *$ & 0.003 & 0.000 & $6.03 \mathrm{E}-15$ & $* * *$ \\
\hline MSP & -2.322 & 1.299 & 0.082127 & - & -1.971 & 0.854 & 0.023575 & $*$ \\
\hline WATER & 4.755 & 0.857 & $<0.000001$ & $* * *$ & 2.242 & 0.614 & 0.000477 & $* * *$ \\
\hline AHM:bio4 & 0.035 & 0.010 & 0.001235 & $* *$ & 0.028 & 0.008 & 0.000401 & $* * *$ \\
\hline AHM:MSP & 0.063 & 0.035 & 0.075775 & . & 0.065 & 0.027 & 0.018987 & $*$ \\
\hline bio4:MSP & 0.004 & 0.002 & 0.045837 & * & 0.003 & 0.001 & 0.006201 & $* *$ \\
\hline AHM:bio4:MSP & $-9.896 \mathrm{E}-05$ & .000048 & 0.046503 & * & $-9.795 E-05$ & 0.00004 & 0.007153 & $* *$ \\
\hline
\end{tabular}

Hallingbäck et al. 2021) specifying a threeterm second-order polynomial model with an interaction term to predict the target trait using climatic variables. Climate variables were selected to provide information about the variation among the test sites. These were: (i) the Annual Heat Moisture index (AHM), calculated as (eqn. 2):

$$
A H M=\frac{M A T+10}{M A P \cdot 10^{-3}}
$$

where MAT is the Mean Annual Temperature $\left({ }^{\circ} \mathrm{C}\right)$ and $M A P$ is the Mean Annual Precipitation (mm); (ii) the bio4 variable (temperature seasonality) from WorldClim (Hijmans et al. 2005), calculated as (eqn. 3):

$$
\text { bio } 4=\frac{\sqrt{\sum_{1}^{12}\left(\text { Tavg }_{i}-M A T\right)^{2}}}{M A T+273.15}
$$

where Tavg is the average temperature of each month; (iii) the total precipitation from May to September (MSP).

The AHM and bio4 describe the relationship between poplar growth and a changing climate in a Mediterranean country (i.e., aridity and continentality respectively), and MSP was added to incorporate the water availability across the growing season. Therefore, the resulting mixed-effects model for each group was (eqn. 4):

$$
\begin{aligned}
\log \left(D B H_{10}\right) & =A H M+A H M^{2}+\text { bio } 4 \\
& + \text { bio } 4^{2}+M S P \\
& +A H M \cdot \text { bio } 4 \cdot M S P+(\text { rnd })
\end{aligned}
$$

where ( $r n d$ ) denotes the random effect among trial sites and is mathematically represented by a different intercept for each clone. To avoid bias resulting from different scaling and aligning operations, spatial predictors were not mathematically modified or standardised. The central (mean) value and the standard deviation used for standardization was known to be different between the dataset and the rasters. Additionally, DBH data were log-transformed, a common procedure in spatial modelling and forest sciences in general (Benito Garzón et al. 2019, Hallingbäck et al. 2021). Even if known to be able to generate biased coefficients in some circumstances (Marchi 2019) this transformation does not impact on variables importance and model predictions. All computations were done in the $\mathrm{R}$ environment ( $\mathrm{R}$ Development Core Team 2020) with the "Ime4" package (Bates et al. 2015).

\section{Results}

The quality check on the interpolation of missing data (i.e., the DBH at age 10) was controlled removing the data when available (i.e., DBH measurements at age 10) and comparing the predicted versus the observed values. On average the interpolation process performed very well, with an average error of $\pm 0.44 \mathrm{~cm}$ (maximum error was $\pm 1.41 \mathrm{~cm}$ ) which corresponds to an average relative absolute error of $\pm 1.62 \%$ (maximum: $\pm 4.53 \%$ ). With the complete 


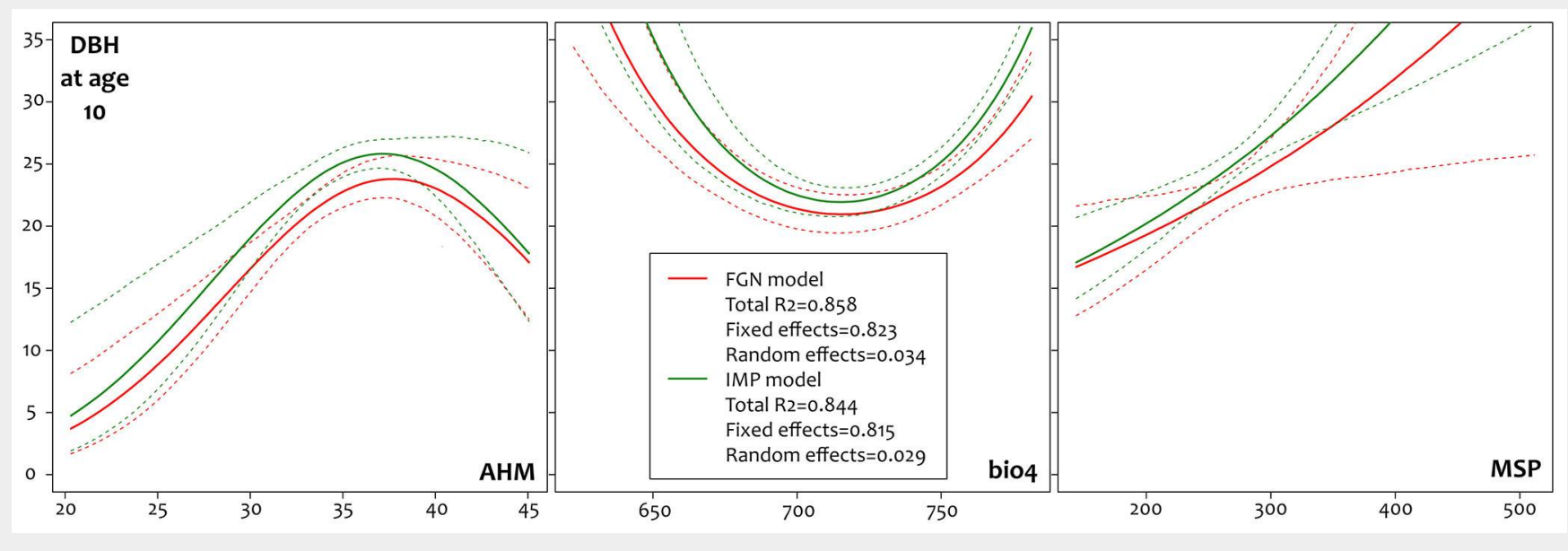

Fig. 3 - Statistical relationship between the measured diameter at breast height (DBH) at age 10 ( $y$-axis, cm) and AHM, bio4 and MSP in the fitted models. The curves for each parameter were generated maintaining the two others on median values.

dataset the fitted mixed-effects models were able to account for $85.8 \%$ of the variance for the FGN clones and $84.4 \%$ for the IMP clones. A small amount of the total variance explained was attributed to random effects (3.4\% for FGN and $2.9 \%$ for IMP) with the fixed effects able to explain $82.3 \%$ and $81.5 \%$ for FGN and IMP, respectively. Most of the variation was explained by the supply of irrigation, and this was larger than the effect of the FGN clones. When models were adjusted by this effect, the aridity predictor (AHM) was more influential than the continentality index (bio4), with a negative coefficient associated to the second-order term and resulting in a convex curve on the $x$-y axes. The bio4 predictor was slightly more influential for IMP than for FGN clones and, conversely, the MSP predictor showed a greater influence in the model fitted for the FGN clones. The estimated coefficients for each model are reported in Tab. 2 and the relative effect of each predictor is shown in Fig. 3. The concavity of the curves from bio4 demonstrates higher productivity at the extremes of the environmental sites tested while the relationship with MSP was linear with a very large slope for both models. However, the large confidence intervals prevented direct comparison between the two URNs calculated. We performed a cross-validation procedure to evaluate and fit the URNs ( $75 \%$ training - $25 \%$ testing repeated 10,000 times) and this showed very low prediction errors, with a mean absolute error of $\pm 2.2 \mathrm{~cm}$ and a mean relative absolute error of $\pm 8.5 \%$.

To show the ecological potential of poplar clones across time and space, the spatial predictions across the whole of Italy were generated removing the irrigation effect. For the current climate (1991-2020 normal period - Fig. 4) the analysis accurately located the "productive core" of poplar cultivation in Italy in the North and across the Po valley for both groups of clones. This region is where most poplar plantations are located and where timber is harvested. However, additional areas were highlighted in the North-West and parts of Central and Southern Italy. The area predicted by the FGN and IMP models were in agreement showing the same spatial pattern, and predicted that IMP clones were (on average) more productive than FGN clones. The comparison in spatial predictions showed that FGN clones were in places more productive than the most recent improved clones (Fig. 5).
Fig. 4 - Expected diameter at breast height (in $\mathrm{cm}$ ) of poplar clones at age 10 without irrigation under the current 30years normal climate

(1991-2020). The experimental sites used for modelling the group are shown as black dots and the statistical extrapolation outside the investigated ecological domain is shown as shaded area.
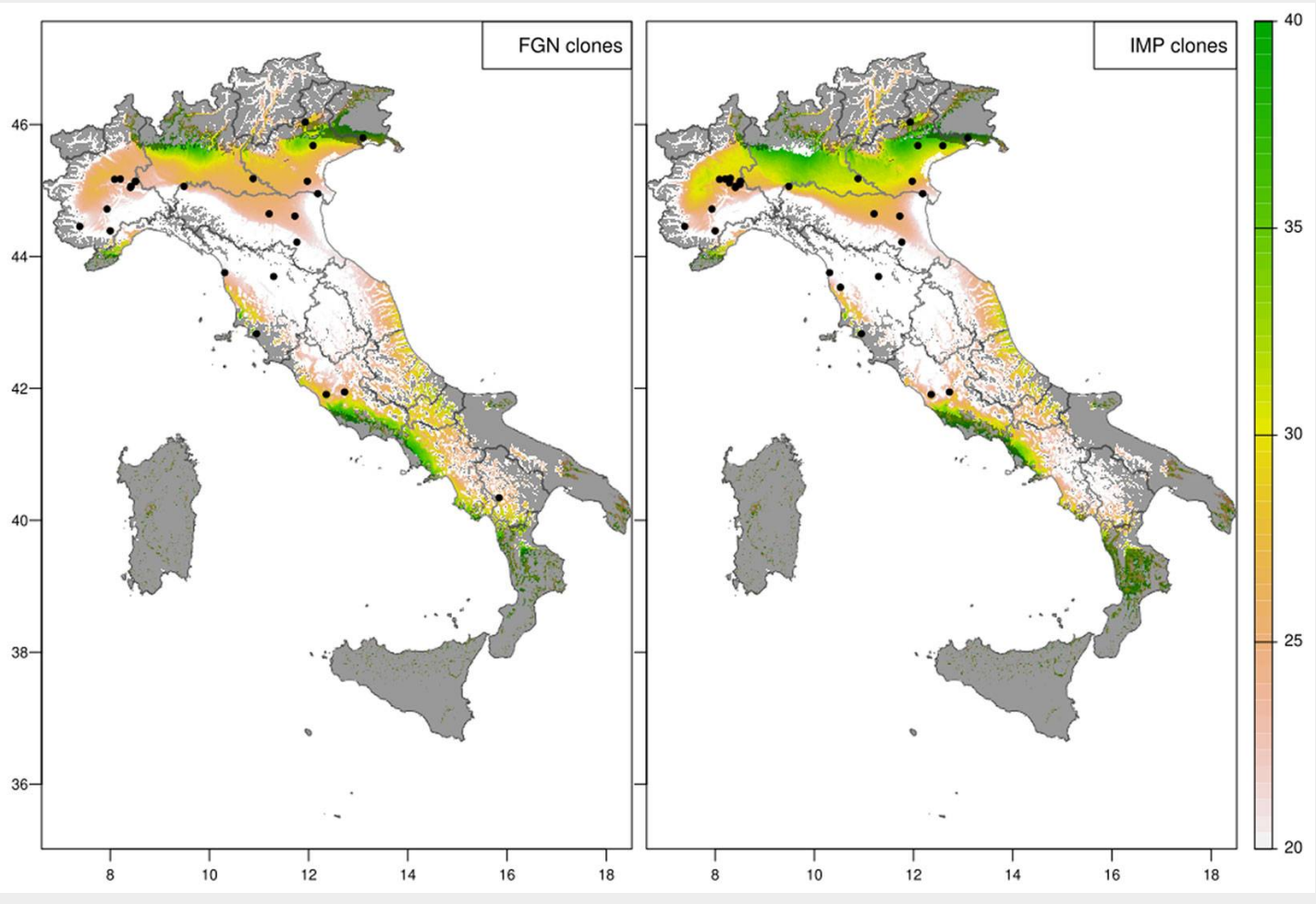
Fig. 5 - Predicted difference in diameter at breast height (in $\mathrm{cm}$ ) at age 10 between poplar FGN and IMP clones across Italy. Positive values indicate that IMP clones are more productive than FGN clones and vice-versa. Values expresses the delta of DBH in centimetres.
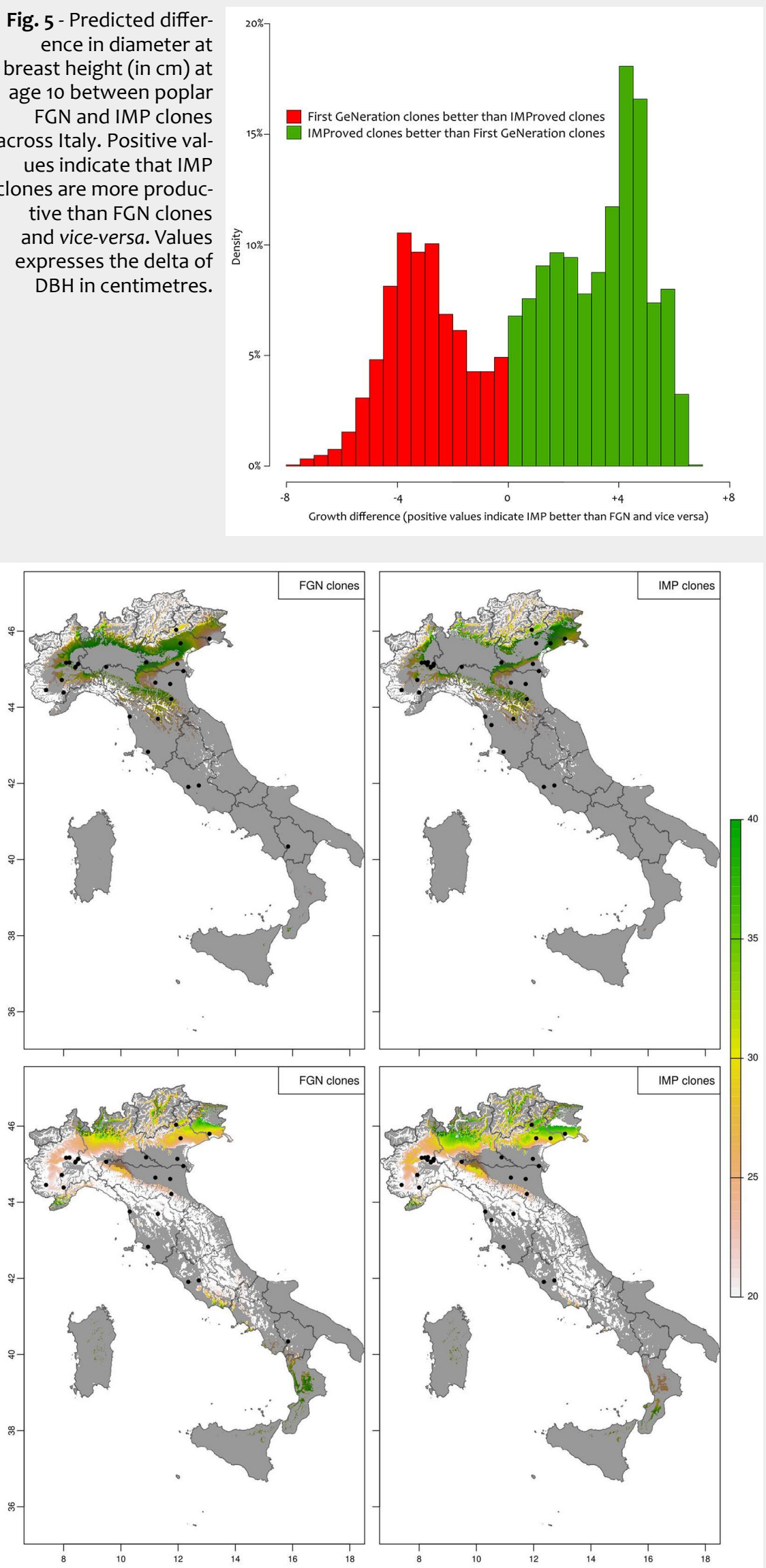

Fig. 6 - Predicted DBH (cm) at age 10 for the two groups of poplar clones in $2040 \mathrm{~s}$ under RCP8.5 using the varianto1 (up) and variant21 (down). The experimental sites used for modelling the group are shown as black dots and the statistical extrapolation outside the investigated ecological domain is shown as shaded area.
When URNs were used to predict the growth and suitable area into the future an uncertain scenario was observed. While projections across RCPs and time-slices were almost in agreement with the expectations of a decrease in land suitability which was delayed for the RCP2.6 scenario compared to the RCP8.5 scenario, a regular trend across time (i.e., 2030s-2040s-2050s) in both RCPs due to a warmer and drier climate was forecast, with a very large difference between variants. Currently this difference was much larger than that observed between RCPs or between time slices. An example is reported in Fig. 6 where the difference between the two variants in the 2040 s for RCP8.5 is proposed.

\section{Discussion}

The URNs we developed showed the possible effects of a changing climate on poplar clone cultivation in Italy. Overall, the improved clonal material, which include MSA material (Higher Environmental Sustainability clones), showed less sensitivity to climatic aridity and a lower effect on growth from irrigation. These results may suggest a possible reduction of cultivation inputs as well as a more stable production of wood assortments in the future than with the current standard clonal types. In addition, the resistance to biotic stress that MSA clones achieve marks them as an important candidate source of reproductive material for poplar cultivation in the future. Adding to the traditional and widely cultivated clones, such as the well-known 'I-214' and here included into the FGN group, new clones selected in recent years show a predicted growth rate comparable with ' $1-214$ ' and better in places. However, several issues remain unclear and must be investigated in greater depth.

Growth rates, carbon sequestration and water supply in a changing climate

In recent decades, due to projected climate change scenarios, the research on hybrid poplar clones has received a strong impulse on fast growing genotypes, droughtresistant and resistant to pathogens (Rennenberg et al. 2010, Polle et al. 2013). In this scenario the breeding activity and clonal selection of new genotypes is aimed mainly at clones with high production capacity associated with a high resistance to the main diseases of poplar (e.g., rust - Melampsoralarici-populina; leaf spot - Marssonina brunnea). Our results showed that IMP clones may be a valuable FRM resource opportunity for the future. In addition to showing some resistance to all the main diseases of poplar trees, improved (IMP) clones show a growth improvement of up to $15 \%$ in volume, compared with the traditional (FGN) clones, and allowing for anticipated harvesting by 1 or 2 years earlier.

As fast-growing tree species, poplars are able to absorb high amounts of $\mathrm{CO}_{2}$ and to sequester carbon in wood used industrially 
for durable products with a long life-time (plywood, furniture, etc.). It has been calculated that a traditional poplar stand (as considered in this study) of 278 plants per hectare can sequester about $25 \mathrm{tha}^{-1} \mathrm{y}^{-1}$ of $\mathrm{CO}_{2}$ (Chiarabaglio et al. 2014) and that there is additionally a positive carbon storage in the soil, comparing agricultural annual crops and poplar stands (Zhang et al. 2020). In addition, a future increase in atmospheric $\mathrm{CO}_{2}$, linked to the greenhouse effect, has been predicted to positively affect the growth and carbon storage of poplar (Gielen et al. 2005). Within this framework our results suggest that IMP clones may be an excellent candidate material to store $\mathrm{CO}_{2}$ in timber and soil in a changing climate with less water availability and warmer temperatures, represented by the AHM term in the URN mixed effects model, due to greater water use efficiency compared with traditional clones. In addition to the research and selection of more adaptable clones, innovative and sustainable cultivation techniques would allow optimization of waste water use derived from urban or agricultural activities (Dimitriou \& Aronsson 2011), or the innovative cultural models of agroforestry that allows irrigation application simultaneously for forest and food-feed crops.

\section{Soil effect on spatial predictions: the} need of expert-knowledge during trials establishment

Undoubtedly, soil physical and chemical properties such as depth and fertility are important components to consider when modelling growth. However, currently there are no high-quality, high-resolution data layers that can be used for such model improvements, thus preventing its inclusion for range-wide modelling purposes. The growth of Populus spp. is particularly linked to soil properties and the lack of soil predictors in this study may leave the door open to questions concerning the real suitability of poplar clones across the spatial extent projected by the URN models. Poplar clones are demanding of soil physical and chemical properties, needing a well-structured, fertile silty-loam soil for successful and profitable cultivation (Winans et al. 2015, Hjelm \& Rytter 2016). Soil physical properties (i.e., micro and macropores in the soil) may influence the water availability across time and space and suggest the need for irrigation, despite rainfall occurring during the growing season. Further research should focus on including soil properties for the models, particularly for available water capacity and cation exchange capacity. While high-quality trial-level data were available for this study, only low resolution spatial layers were available and found unsuitable for modelling. This shortcoming relies on the fact that while climate can be interpolated to obtain spatial layers from meteo-stations by means of different methods (Daly et al. 2008, Galván et al. 2014, Harris et al.
2020), such techniques are much less reliable for soil properties, given the lower sampling and the lack of spatial autocorrelation or external drift. Despite the omission of soil in the model, the climatic suitability of clonal material can provide an initial spatial focus for poplar trials in the future, with the detail of soil properties assessed as part of the potential site assessment. This study therefore provides an important initial filter to locate potential areas in regions where clonal material can be tested. In addition, soil properties that are essential for poplar cultivation can be written into a decision support tool that delivers the climatic suitability of specific clones in a region (Ray et al. 2009).

\section{Modelling uncertainties in spatial and} temporal extrapolation: the need for a larger network of trials

Our analysis investigated the whole lifespan of poplar cultivation and not just the early establishment stage of tree growth, which is less common in the forestry sector (Müller et al. 2020). To evaluate the quality and productivity of forest material, provenances, clones and other reproductive material, it is best to test the material in common garden trials and compare traits with older material, used as a reference threshold. There is much literature concerning tree breeding activities, models and the climatic shift of tree species niches across time and space (Boiffin et al. 2017, Benito Garzón et al. 2019) and local material is not always the best choice under climate change projections (Chakraborty et al. 2015, Marchi \& Cocozza 2021). Beyond any modelling activities, however, large ecological domains must be investigated to derive reliable data on growth performance of forest tree species. The dataset we used in this work can be considered a good sample of a wide spectrum of climates across Italy. With an observed ecological range of 4.97 ${ }^{\circ} \mathrm{C}$ in mean annual temperature (between $11.5^{\circ} \mathrm{C}$ at Feltre site and $16.5^{\circ} \mathrm{C}$ at $\mathrm{Az}$. Ovile site) and a range in total annual precipitation of $639.8 \mathrm{~mm}$ (max: $1176 \mathrm{~mm}$ - Az. Volpares site; min: $536 \mathrm{~mm}$ - Marsicovetere site), our dataset can investigate a large ecological domain, resulting in a good predictive potential of URNs able to project the growth of poplars into the future. However, the comparison between the two clonal groups and the proposed models must be considered with respect to the large confidence intervals for each model parameter. This was mainly due to a large degree of variation within each clonal group we proposed, and by modelling single-clone RNs may allow us to reduce the variation, as would modelling larger datasets across wider environmental gradients. Both the range, and the distribution of data are important issues when assessing the results from statistical models. In this study a shortcoming of our database was the uneven distribution of clones across the sites (partially solved by the grouping) as well as the asymmetric distribution of the trials, both geographically and environmentally. Most of the sites are clustered in the Po valley and very few sites are at the leading and trailing edge of the ecological range. Low AHM and low bio4 values were not investigated at all (e.g., $\mathrm{AHM}<30$ and bio4<700) and neither were drier conditions (e.g., $\mathrm{AHM}>40$ ) which play a key role for future ecological range of the data (i.e., the climate of maximum or minimum growth) which also affects the use of the models for future scenarios with a rapid change of growth with climate variables. This requires an enlargement of the network that includes old and new clones to add to historical data, and predicting the growth of the same clones in the same sites but under past climatic conditions (Pretzsch et al. 2014).

The need for high-quality data must not shade the requirement of reliable future projections. Climatologists and atmospheric scientists are improving future scenarios with new GCM and RCM models, and climate projections based on international COP agreements. Indeed, new frameworks and new knowledge and scenarios will soon be delivered under the CMIP6 (Gidden et al. 2019, Cook et al. 2020). Unfortunately, cross validation on future projections cannot be performed: therefore ecological modellers must rely on conceptual schemes and use multiple outputs to manage uncertainties (Hallingbäck et al. 2021). In this work, more focused on reaction norms on historical and current climate than on future scenarios, we have shown a partial example of how difficult future predictions can be. The use of the two different UKCP18 variants (i.e., the standard UKCP18 - varianto1, and the least extreme projection according to ClimateDT - variant21) produced completely diverging scenarios after the 2030s. In addition, the projection made with varianto1 was mostly from extrapolation, with high uncertainty. For these reasons, much more effort is needed to support decision makers with additional data. Further, researchers must test genotypes outside the "expected" ecological niche. In this framework we provide spatial projections for the current time (i.e., 1991-2020 climatic normal period) and the 2030 s to represent a valuable guideline to plan the future establishment of additional trials using the same materials to be tested outside the environment we have observed in this work. Furthermore, it is important to point out that future scenarios are highly uncertain, not only due to the wide range of possible climate conditions but also because the future dynamics of pests and diseases are not easily predictable. However, in this scenario the use of MSA clones may fix this problem, given their ability to resist to the two main biotic threats (rusts and aphids).

\section{Conclusions}

High quality timber assortments and 
wood products in general are important to society and provide long-term methods of sequestering carbon. Durable products and fast-growing trees are efficient at reducing the amount of $\mathrm{CO}_{2}$ in the air and mitigate the emissions. This is much more evident when compared to bioenergy and the use of biomass in general, where the total amount of carbon components is maintained at stable level and not sequestered for long periods. Poplars are among the most important forest tree species used in agroforestry systems and we have provided URNs to show the improvement that can be made to poplar cultivation under climate change scenarios. However, the need for future assessments is demanding, and additional efforts should be made to improve the dataset (and predictions) we have developed. Different reaction norms could be expected in the future from more extensive experimental trials, showing a more stable production of clones across the ecological gradients.

\section{Acknowledgements}

This research work was developed in the framework of WP1 and WP5 of the Horizon 2020 B4EST project "Adaptive BREEDING for productive, sustainable and resilient FORESTs under climate change", UE Grant Agreement 773383.

\section{References}

Bates D, Mächler M, Bolker BM, Walker SC (2015). Fitting linear mixed-effects models using Ime4. Journal of Statistical Software 67: 148. - doi: 10.18637/jss.v067.io1

Benito Garzón M, Robson TM, Hampe A (2019). $\triangle$ TraitSDM: species distribution models that account for local adaptation and phenotypic plasticity. New Phytologist 222: 1757-1765. - doi: 10.1111/nph.15716

Bergante S, Facciotto G, Marchi M (2020). Growth dynamics of "Imola" poplar clone (Populus $\times$ canadensis Mönch) under different cultivation inputs. Annals of Silvicultural Research 44: 71-79. - doi: 10.12899/asr-1934

Berlin M, Persson T, Jansson G, Haapanen M, Ruotsalainen S, Bärring L, Gull BA (2016). Scots pine transfer effect models for growth and survival in Sweden and Finland. Silva Fennica 50: 121. - doi: 10.14214/sf.1562

Boiffin J, Badeau V, Bréda N (2017). Species distribution models may misdirect assisted migration: insights from the introduction of Douglasfir to Europe. Ecological Applications 27: 446457. - doi: 10.1002/eap.1448

Booth TH (2018). Species distribution modelling tools and databases to assist managing forests under climate change. Forest Ecology and Management 430: 196-203. - doi: 10.1016/j.foreco. 2018.08.019

Chakraborty D, Wang T, Andre K, Konnert M, Lexer MJ, Matulla C, Schueler S (2015). Selecting populations for non-analogous climate conditions using universal response functions: the case of douglas-fir in central Europe. PLoS One 10: 1-21. - doi: 10.1371/journal.pone.0136357

Chakraborty D, Wang T, Andre K, Konnert M, Lexer MJ, Matulla C, Weienbacher L, Schueler S
(2016). Adapting Douglas-fir forestry in Central Europe: evaluation, application, and uncertainty analysis of a genetically based model. European Journal of Forest Research 135: 919936. - doi: 10.1007/s10342-016-0984-5

Chiarabaglio PM, Allegro G, Rossi A, Savi L (2014). Studi sulla sostenibilità della pioppicoltura in Lombardia [Studies on sustainability of poplar cultivation in Lombardy]. Sherwood 206: 5-8. [in Italian]

Cook BI, Mankin JS, Marvel K, Williams AP, Smerdon JE, Anchukaitis KJ (2020). Twenty-first century drought projections in the CMIP6 forcing scenarios. Earth's Future 8: 1-20. - doi: 10.1029/ 2019EFo01461

Corona P, Chianucci F, Marcelli A, Gianelle D, Fattorini L, Grotti M, Puletti N, Mattioli W (2020). Probabilistic sampling and estimation for largescale assessment of poplar plantations in Northern Italy. European Journal of Forest Research 139: 981-988. - doi: 10.1007/s10342-02001300-9

Daly C, Halbleib M, Smith JI, Gibson WP, Doggett MK, Taylor GH, Curtis J, Pasteris PP (2008). Physiographically sensitive mapping of climatological temperature and precipitation across the conterminous United States. International Journal of Climatology 28: 2031-2064. - doi: 10.1002/joc.1688

Dimitriou I, Aronsson P (2011). Wastewater and sewage sludge application to willows and poplars grown in lysimeters - Plant response and treatment efficiency. Biomass and Bioenergy 35: 161-170. - doi: 10.1016/j.biombioe.2010.08.019 Elith J, Graham CH, Anderson RP, Dudík M, Ferrier S, Guisan A, Hijmans RJ, Huettmann $F$, Leathwick JR, Lehmann A, Li J, Lohmann LG, Loiselle BA, Manion G, Moritz C, Nakamura M, Nakazawa Y, Overton JMC, Peterson AT, Phillips SJ, Richardson K, Scachetti-Pereira R, Schapire RE, Soberón J, Williams S, Wisz MS, Zimmermann NE (2006). Novel methods improve prediction of species' distributions from occurrence data. Ecography 29 (2): 129-151. doi: 10.1111/j.2006.0906-7590.04596.x

Fréjaville T, Fady B, Kremer A, Ducousso A, Benito Garzón M (2019). Inferring phenotypic plasticity and local adaptation to climate across tree species ranges using forest inventory data. Global Ecology and Biogeography 28 (9): 1-34. doi: 10.1111/geb.12930

Galván L, Olías M, Izquierdo T, Cerón JC, Fernández De Villarán R (2014). Rainfall estimation in SWAT: an alternative method to simulate orographic precipitation. Journal of Hydrology 509: 257-265. - doi: 10.1016/j.jhydrol.2013.11.044 Gidden MJ, Riahi K, Smith SJ, Fujimori S, Luderer G, Kriegler E, Van Vuuren DP, Van Den Berg M, Feng L, Klein D, Calvin K, Doelman JC, Frank S, Fricko O, Harmsen M, Hasegawa T, Havlik P, Hilaire J, Hoesly R, Horing J, Popp A, Stehfest E, Takahashi K (2019). Global emissions pathways under different socioeconomic scenarios for use in CMIP6: a dataset of harmonized emissions trajectories through the end of the century. Geoscientific Model Development 12: 1443-1475. - doi: 10.5194/gmd-12-1443-2019

Gielen B, Calfapietra C, Lukac M, Wittig VE, De Angelis P, Janssens IA, Moscatelli MC, Grego S, Cotrufo MF, Godbold DL, Hoosbeek MR, Long SP, Miglietta F, Polle A, Bernacchi CJ, Davey PA,
Ceulemans R, Scarascia-Mugnozza GE (2005). Net carbon storage in a poplar plantation (POPFACE) after three years of free-air $\mathrm{CO}_{2}$ enrichment. Tree Physiology 25: 1399-1408. - doi: 10.1093/treephys/25.11.1399

Hallingbäck HR, Burton V, Vizcaíno-Palomar N, Trotter F, Liziniewicz M, Marchi M, Berlin M, Ray D, Benito-Garzón M (2021). Managing uncertainty in Scots pine range-wide adaptation under climate change. Frontiers in Ecology and Evolution 9 (724051): 1-18. - doi: 10.3389/fevo. 2021.724051

Harris I, Osborn TJ, Jones P, Lister D (2020). Version 4 of the CRU TS monthly high-resolution gridded multivariate climate dataset. Scientific Data 7: 109. - doi: 10.1038/s41597-020-0453-3

Hemery GE, Savill PS, Thakur A (2005). Height growth and flushing in common walnut (Juglans regia L.): 5-year results from provenance trials in Great Britain. Forestry 78: 121-133. - doi: 10.1093/forestry/cpio12

Hijmans RJ, Cameron SE, Parra JL, Jones G, Jarvis A (2005). Very high resolution interpolated climate surfaces for global land areas. International Journal of Climatology 25: 1965-1978. doi: 10.1002/joc.1276

Hjelm K, Rytter L (2016). The influence of soil conditions, with focus on soil acidity, on the establishment of poplar (Populus spp.). New Forests 47: 731-750. - doi: 10.1007/s11056-016-9541-9 Isaac-Renton MG, Roberts DR, Hamann A, Spiecker H (2014). Douglas-fir plantations in Europe: a retrospective test of assisted migration to address climate change. Global Change Biology 20: 2607-2617. - doi: 10.1111/gcb.12604

Lefèvre F, Barsoum N, Heinze B, Kajba D, Rotach $P$, Vries De SMG (2001). In situ conservation of Populus nigra. International Plant Genetic Resources - IPGRI/EUFORGEN, Rome, Italy, pp. 58. [online] URL: http://books.google.com/books? id=I_COTUxowtEC

Lowe JA, Bernie D, Bett P, Bricheno L, Brown S, Calvert D, Clark R, Eagle K, Edwards T, Fosser G, Fung F, Gohar L, Good P, Gregory J, Harris G, Howard T, Kaye N, Kendon E, Krijnen J, Maisey P, McDonald R, Mclnnes R, McSweeney C, Mitchell JF, Murphy J, Palmer M, Roberts C, Rostron J, Sexton D, Thornton H, Tinker J, Tucker S, Yamazaki K, Belcher S (2019). UKCP18 science overview report version 2.0. Met Office, London, UK, pp. 79.

Marchi M (2019). Nonlinear versus linearised model on stand density model fitting and stand density index calculation: analysis of coefficients estimation via simulation. Journal of Forestry Research 30: 1595-1602. - doi: 10.1007/s116 76-019-00967-0

Marchi M, Castellanos-Acuña D, Hamann A Wang T, Ray D, Menzel A (2020). ClimateEU, scale-free climate normals, historical time series, and future projections for Europe. Scientific Data 7: 428. - doi: 10.1038/s41597-020-007 63-0

Marchi M, Cocozza C (2021). Probabilistic provenance detection and management pathways for Pseudotsuga menziesii (Mirb.) Franco in Italy using climatic analogues. Plants 10 (2): 215. doi: 10.3390/plants10020215

Matyas C (1994). Modeling climate change effects with provenance test data. Tree Physiology 14: 797-804. - doi: 10.1093/treephys/14.7-8- 
9.797

Müller M, Kempen T, Finkeldey R, Gailing $\mathrm{O}$ (2020). Low population differentiation but high phenotypic plasticity of European beech in Germany. Forests 11: 1-14. - doi: 10.339o/f11121354

O’Neill GA, Hamann A, Wang TL (2008). Accounting for population variation improves estimates of the impact of climate change on species' growth and distribution. Journal of Applied Ecology 45: 1040-1049. - doi: 10.1111/j.1365-2664. 2008.01472.x

Pecchi M, Marchi M, Burton V, Giannetti F, Moriondo M, Bernetti I, Bindi M, Chirici G (2019). Species distribution modelling to support forest management. A literature review. Ecological Modelling 411: 108817. - doi: 10.1016/j.ecolm odel.2019.108817

Polle A, Janz D, Teichmann T, Lipka V (2013). Poplar genetic engineering: promoting desirable wood characteristics and pest resistance. Applied Microbiology and Biotechnology 97 (13): 5669-5679. - doi: 10.1007/s00253-013-4940-8 Pretzsch H (2009). Forest dynamics, growth and yield - From measurement to model. SpringerVerlag, Berlin, Heidelberg, Germany, pp. 423491. - doi: 10.1007/978-3-540-88307-4

Pretzsch H, Biber P, Schütze G, Uhl E, Rötzer T (2014). Forest stand growth dynamics in Central Europe have accelerated since 1870 . Nature Communications 5 (1): 1065. - doi: 10.1038/ncom ms5967

Pukkala T (2017). Transfer and response functions as a means to predict the effect of climate change on timber supply. Forestry 90: 573-580.
- doi: 10.1093/forestry/cpx017

10.1016/j.ecolind.2019.105891

R Development Core Team (2020). R: a language and environment for statistical computing. $R$ Foundation for Statistical Computing, Vienna, Austria. [online] URL: http://www.r-project.org Ray D, Xenakis G, Tene A, Black K (2009). Developing a site classification system to assess the impact of climate change on species selection in Ireland. Irish Forestry 66: 101-122. [online] URL: http://www.researchgate.net/publication/ 33853539

Rennenberg $\mathrm{H}$, Wildhagen $\mathrm{H}$, Ehlting B (2010). Nitrogen nutrition of poplar trees. Plant Biology 12: 275-291. - doi: 10.1111/j.1438-8677.2009. 00309.x

Schreiber SG, Hamann A, Hacke UG, Thomas BR (2013). Sixteen years of winter stress: an assessment of cold hardiness, growth performance and survival of hybrid poplar clones at a boreal planting site. Plant, Cell and Environment 36: 419-428. - doi: 10.1111/j.1365-3040.2012. 02583.X

Schueler S, Falk W, Koskela J, Lefèvre F, Bozzano $M$, Hubert J, Kraigher H, Longauer R, Olrik DC (2014). Vulnerability of dynamic genetic conservation units of forest trees in Europe to climate change. Global Change Biology 20: 1498-1511. doi: $10.1111 / g c b .12476$

Tang Y, Winkler JA, Viña A, Wang F, Zhang J, Zhao Z, Connor T, Yang $\mathrm{H}$, Zhang $\mathrm{Y}$, Zhang $\mathrm{X}$, Li $X$, Liu J (2020). Expanding ensembles of species present-day and future climatic suitability to consider the limitations of species occurrence data. Ecological Indicators 110: 105891. - doi:
Vizcaíno-Palomar N, Fady B, Alía R, Raffin A, Mutke S, Benito-Garzón M (2020). The legacy of climate variability over the last century on populations' phenotypic variation in tree height. Science of the Total Environment 749: 141454. doi: 10.1016/j.scitotenv.2020.141454

Wang T, Hamann A, Spittlehouse D, Carroll C (2016). Locally downscaled and spatially customizable climate data for historical and future periods for North America. PLoS One 11 (6): e0156720. - doi: 10.1371/journal.pone.0156720

Wang T, O’Neill GA, Aitken SN (2010). Integrating environmental and genetic effects to predict responses of tree populations to climate 20: 153-163.

Winans KS, Tardif AS, Lteif AE, Whalen JK (2015). Carbon sequestration potential and cost-benefit analysis of hybrid poplar, grain corn and hay cultivation in southern Quebec, Canada. Agroforestry Systems 89 (3): 421-433. - doi: 10.1007/ s10457-014-9776-4

Zhang Y, Tian Y, Ding S, Lv Y, Samjhana W, Fang $S$ (2020). Growth, carbon storage, and optimal rotation in poplar plantations: a case study on clone and planting spacing effects. Forests 11: 115. - doi: $10.3390 / F 11080842$

\section{Supplementary Material}

Tab. S1 - Full list of clones used in this study and distribution across groups.

Link: Marchi_3989@supplo01.pdf 